\title{
Correction to: Examining the interaction of fast-food outlet exposure and income on diet and obesity: evidence from 51,361 UK biobank participants
}

Thomas Burgoine ${ }^{1 *}$, Chinmoy Sarkar ${ }^{2}$, Chris J. Webster ${ }^{2}$ and Pablo Monsivais ${ }^{1,3}$

\section{Correction}

The original article [1] contained a number of minor copyediting errors in the main body. These errors have now been corrected.

Furthermore, these errors were mistakenly introduced by the Production team managing this article and, as such were not the fault of the authors.

\begin{abstract}
Author details
'UKCRC Centre for Diet and Activity Research (CEDAR), MRC Epidemiology Unit, University of Cambridge School of Clinical Medicine, Box 285 Institute of Metabolic Science, Cambridge Biomedical Campus, Cambridge CB2 OQQ, UK. ${ }^{2}$ Healthy High Density Cities Lab, HKUrbanLab, University of Hong Kong, Knowles Building, Pokfulam Road, Hong Kong, Special Administrative Region, China. ${ }^{3}$ Present Address: Department of Nutrition and Exercise Physiology, Elson S. Floyd College of Medicine, Washington State University, Spokane, Washington, USA.
\end{abstract}

Received: 31 July 2018 Accepted: 13 August 2018

Published online: 25 September 2018

\section{Reference}
1. Burgoine T. et al., Examining the interaction of fast-food outlet exposure and income on diet and obesity: evidence from 51,361 UK biobank participants, Int J Behav Nutr Phys Act, 2018;15:71. https://doi.org/10.1186/ s12966-018-0699-8.

\footnotetext{
*Correspondence: tb464@medschl.cam.ac.uk

'UKCRC Centre for Diet and Activity Research (CEDAR), MRC Epidemiology Unit, University of Cambridge School of Clinical Medicine, Box 285 Institute of Metabolic Science, Cambridge Biomedical Campus, Cambridge CB2 OQQ UK
}

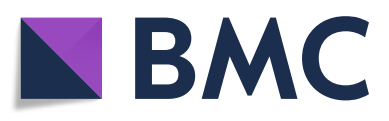

(c) The Author(s). 2018 Open Access This article is distributed under the terms of the Creative Commons Attribution 4.0 International License (http://creativecommons.org/licenses/by/4.0/), which permits unrestricted use, distribution, and reproduction in any medium, provided you give appropriate credit to the original author(s) and the source, provide a link to the Creative Commons license, and indicate if changes were made. The Creative Commons Public Domain Dedication waiver (http://creativecommons.org/publicdomain/zero/1.0/) applies to the data made available in this article, unless otherwise stated. 